\title{
Comparison-concave utility and following behaviour in social and economic settings
}

\author{
Andrew E. Clark ${ }^{\mathrm{a}}$, Andrew J. Oswald ${ }^{\mathrm{b}, *}$ \\ ${ }^{a}$ CNRS and LEO-CRESEP, University of Orléans, Orléans, France \\ ${ }^{\mathrm{b}}$ Department of Economics, University of Warwick, Coventry, CV4 7AL, UK
}

\begin{abstract}
This paper describes a theory of rational emulation and deviance. It assumes that individuals care about relative position (or 'status'), and constructs a model of decisionmaking in social and economic settings. The analysis shows why individuals who want to be different from others will, paradoxically, find it rational to imitate other people. The paper also provides a choice-theoretic foundation for a number of ideas in the social psychology and economics literatures. The central point of the paper is that concern about relative position or rank is, by itself, insufficient to bring about emulation. The reaction of an individual to others' behaviour depends crucially on the curvature of the comparison term in their utility function: individuals with comparison-concave utility follow others while those with comparison-convex utility act deviantly. (C) 1998 Elsevier Science S.A. All rights reserved.
\end{abstract}

Keywords: Comparisons; Status; Concavity; Following; Deviance

JEL classification: A14; D62; D81

\section{Introduction}

The aim of this paper is to develop a model of behaviour in which individuals care about, and respond to, the actions of others. The analysis begins with a question that is central to social and economic theory, namely, that of why individuals follow each other's actions. It develops a theory of conformity and

*Corresponding author. Tel.: +44 1203 523510; E-mail: a.j.oswald@warwick.ac.uk 
deviance. A choice-theoretic rationale is given for the formulae contained in the social psychologist's models known as equity theory (Adams, 1963, 1965) and social exchange theory (Homans, 1961). Other sociological ideas, about the importance of status and the absence of a strong role for private rates-of-return, emerge from within the framework. The analysis also provides a choice-theoretic justification for a class of models exemplified by Akerlof (1980), Jones (1984) and Kandel and Lazear (1992).

Human beings seem to have a deeply-rooted need to conform, to copy, and to act fashionably. Examples of this kind of behaviour are the stuff of everyday life. The desire to fit in and to follow others probably helps to determine, among other things, the clothes we wear, the length of our hair, our weight, how many children we raise, the depth of our sun-tan, the size of vehicle in our driveway, the colour of the garage to which that driveway leads, the number plate on the vehicle in front of the garage, the type of food we eat, the shape of our teeth, where we go on holiday, and our preferences about issues as diverse as religion and contact lenses. Herd behaviour in more narrowly economic situations can be seen in, for example, commodity and financial markets, and in markets for collectibles such as art and antiques. Labour markets provide a rich array of further examples-including how hard to work, whether to join a union, and how large a pay rise to demand. A more sociological example is the twentieth century desire to be as thin as, or thinner than, one's neighbour. 'Following' behaviour appears to be ubiquitous in social and economic settings.

The economist's natural response to these observations is either to question their validity or to suggest that standard models may be able to explain them. This paper is based upon the view that there is something called fashion and that it enters both social and economic life. The paper recognises that people sometimes have good, non-mysterious reasons to imitate one another: changes in technology can generate apparent copying behaviour as agents all switch toward a new product or activity; and new information, about a coming thunderstorm or a political opinion poll, does the same. Yet people appear to emulate one another in too many situations to make such explanations sufficient.

The English language recognizes the importance of conformist behaviour. It contains a plethora of words to capture the idea: 'fads', 'trendy', 'modish', 'fashion', 'all the rage', 'peer pressure', 'in style', 'bandwagon effects', 'craze', 'cult' and 'vogue'. If reality corresponded to the world of the conventional economics textbook, it is not easy to see why these words would be needed in English (or any other language). Traditional economic models assume self-interest, rationality, and exogenous preferences. They do not lead one to expect human beings to be moulded by fashion.

It is tempting to see following behaviour, especially in social situations, as driven by a kind of irrational need to fit in. On this view, to keep up with the Jones' is a sign of weakness, an emotional response rather than a logical choice. Many economists might be willing to adopt a milder version of this view, and to 
argue that emulation in economic situations can be explained by appropriately adapting standard theory, while imitative actions in sociological settings may be less explicable but are not the concern of economic theorists.

The object of the paper is to argue that a single model is capable of explaining a variety of emulative activity ${ }^{1}$, and that a concern for status or relative position is not by itself sufficient to ensure emulation. The model relies on two assumptions: the first is that utility depends in part upon relative position (or 'status') and the second is that this comparison component of utility is concave. Under such assumptions, a common framework can be used to predict a range of imitative phenomena. Unlike the work by Akerlof (1980), Jones (1984) and Kandel and Lazear (1992), the paper does not assume that individuals wish to be similar.

The paper's broader purpose is to blend economic and sociological ideas within one framework. Section 2 sets out the basic model and shows how it predicts following behaviour. Section 3 presents some simulations of the model using quadratic functional forms, and demonstrates how fashion cycles may come about; it also shows that, with emulative behaviour, an increase in a good's marginal utility may reduce its consumption in equilibrium. Section 4 concludes.

\section{A model encompassing economic and social elements}

To attempt to construct a theory of social and economic behaviour, it is necessary to blend two traditionally distinct ways of thinking ${ }^{2}$. The dichotomy is accurately and colourfully captured in a recent description by Jon Elster:

"One of the most persistent cleavages in the social sciences is the opposition between two lines of thought conveniently associated with Adam Smith and Emile Durkheim, between homo economicus and homo sociologicus. Of these, the former is supposed to be guided by instrumental rationality, while the behaviour of the latter is dictated by social norms. The former is 'pulled' by the prospect of future rewards, whereas the latter is 'pushed' by

\footnotetext{
${ }^{1}$ Earlier work in economics on this topic includes Akerlof (1980) and Jones (1984). A number of recent papers attempt to produce theories of herd behaviour and related phenomena: see Banerjee (1992), Bernheim (1994), Bulow and Klemperer (1991), Cole et al. (1992), Fershtman and Weiss (1992) and Scharfstein and Stein (1990). These models stress informational issues: people learn from watching what others do. It is not clear the models can explain fashion in social settings. A model closer to ours is Rauscher (1992). For a socio-biological model, see Steuer (1989). For a survey, and a number of extensions, see Sinclair (1990).

${ }^{2}$ Akerlof (Akerlof, 1980, 1982) and Frank (Frank, 1984a,b, 1985) have been prominent in the work introducing psychological and sociological ideas into economics. Becker's (Becker, 1974, 1976) work helped to begin this movement. Abell (Abell, 1971, 1992) and Coleman (1991) argue for the use of rational choice models in sociological analysis.
} 
quasi-inertial forces .... The former is easily caricatured as a self-contained, asocial atom, and the latter as the mindless plaything of social forces..."

Elster, $1991^{3}$

The model developed in the paper recognises this dichotomy. It assumes that individuals are motivated by two kinds of rewards (one direct, the other from social comparison). Within this framework, however, it assumes self-interest. Although one of the paper's aims is to explain behaviour that is traditionally thought of as sociological, the analysis posits no irrationality, nor any actions driven by an emotional requirement to conform. The actors in the model do, in general, abide by social and economic norms. The norms are equilibria produced by the independent actions of rational maximizers.

The framework to be constructed might be thought of as a formalization of the sociologist's long-standing concern with status, or as a generalization of the ideas of Veblen (1949):

"The complex of problems associated with patterns of class and status has always been a focal point of sociological inquiry, just as kinship patterns have been such a point for the social anthropologist in the study of tribal societies. In this sense we could say that sociology brought to the social sciences a new principle or point of view; namely, to observe social phenomena from the aspect of the ranking of individuals and groups in the social hierarchy."

\section{p. 84, Bottomore (1966).}

"The end sought by accumulation is to rank high in comparison with the rest of the community.... So long as the comparison is distinctly unfavourable

\footnotetext{
${ }^{3}$ Elster's (Elster, 1991) main purpose is to object to the idea that norms of social behaviour might be viewed as the result of private maximizing behaviour. It is thus different from this paper. Nevertheless, Elster often argues in his book in a way that sounds compatible with the mathematical analysis developed here. For example, discussing how individuals in primitive societies feel it necessary to under-achieve for fear of envy and of being thought witches, Elster makes two points:

1. "there is certainly something to this picture... it suggests a sense in which envy does indeed serve as the glue and cement of society, by relentlessly repressing deviants, and, more fundamentally, the desire to deviate in the first place."

2. "... the would-be innovator is afraid that success will cause envy and that failure will expose him to spite. The over-arching norm, don't stick your neck out, acts as a deterrent..." (p. 262).
}

These loosely correspond to the two central formal assumptions used in this paper, namely, that people care about comparisons to others and are risk-averse, i.e. the comparison component of their utility function is concave. 
to himself, the normal, average individual will live in chronic dissatisfaction with his present lot...",

"Relative success, tested by an invidious pecuniary comparison with other men, becomes the conventional end of action."

p. 33, T. Veblen, 1949.

The paper assumes, following Veblen (1949) and Festinger (1954), that individuals constantly compare themselves to others. The most natural interpretation is that they feel in competition with human beings like themselves, and enjoy a sense of well-being when they out-perform their peers, or obtain a sense of failure and envy when they rank poorly besides those peers. Much of social psychology rests upon notions of this kind. Classic sources include Festinger (1954), Stouffer et al. (1949), Homans (1961) and Adams (1963). Modern textbook treatments include Argyle (1989), Warr (1985) and Weyant (1986). Sociology, and a segment of economics, also takes seriously the assumption that feelings of relative deprivation are important. Sociological literature includes Davis (1959), Pollis (1968) and Runciman (1966). The economics literature includes Duesenberry ${ }^{4}$ (1949), Layard (1980) and Frank (1985).

\subsection{The model}

Let $a$ be an action of some economic or social kind. Assume that it gives utility both directly and, through status or relative position, indirectly. Assume that action $a$ is costly, and let $a^{*}$ be the mean (or some other measure) of other people's actions.

Define the agent's utility function in one of two ways. The first specification, which will be termed an additive comparisons model, has utility given by

$$
U=s v\left(a-a^{*}\right)+(1-s) u(a)-c(a)
$$

The function $v$ is to be thought of as capturing the utility from comparisons. Its first derivative will be taken to be positive; its second derivative may be positive

\footnotetext{
${ }^{4}$ The literature on relative deprivation is large. Outside economics it includes Adams (Adams, 1963, 1965), Bernstein and Crosby (1980), Crosby (1976), Davis (1959), Festinger (1954), Homans (1961), Lawler (1971), Pollis (1968), Pritchard (1969), Runciman (1966), Stouffer et al. (1949), Walster et al. (1973), and Weik (1966). Inside economics it includes, in addition to references cited earlier, Baxter (1988), Boskin and Sheshinski (1978), Clark and Oswald (1996), Duesenberry (1949), Gylfason and Lindbeck (1984), Hochman and Rogers (1969), Kapteyn and Van Herwaarden (1980), Kosicki (1987), Lommerud (1989), Layard (1980), Oswald (Oswald, 1979, 1983), Sen (1983), Scitovsky (1976), Trevithick (1976), Van de Stadt et al. (1985), and Wood (1978). Robson (1992) is a recent application that discusses status.
} 
or negative (corresponding to comparison-convex or comparison-concave utility). Thus people enjoy surpassing others' actions. This, in our model, is what gives status. The function $u$ is increasing and concave in $a$. The cost function $c(a)$ is increasing and convex in $a$. The variable $s$ is a parameter in the unit interval.

An alternative specification, a ratio comparisons model, assumes utility:

$$
U=s v\left(\frac{a}{a^{*}}\right)+(1-s) u(a)-c(a) .
$$

In this case the determinant of status is the ratio (rather than the difference) of action $a$ to others' actions $a^{*}$. As before, an increase in $a$ raises utility both through a direct effect upon $u(a)$ and an indirect effect, acting through the relative value of the action, upon $v\left(a / a^{*}\right)$. For the sake of clarity, Eq. (1) and (2) assume more separability than is strictly required.

These specifications have the feature that utility depends upon a convex combination of a direct private component of utility and a status- or comparisonoriented element of utility. The weights, $(1-s)$ and $s$, provide a simple way to capture the mix of effects. As $s \rightarrow 0$, the traditional economist's model holds. Preferences are private and self-interested; agents do not look over their shoulders to see what other individuals are doing. As $s \rightarrow 1$, only relative position matters, and an extreme 'sociological' model applies. Relativities play a paramount role in such a model.

To choose his or her optimal action, the individual with concern for additive comparisons maximizes expression (1). For an interior maximum

$$
s v^{\prime}\left(a-a^{*}\right)+(1-s) u^{\prime}(a)-c^{\prime}(a)=0 .
$$

The first term is the marginal benefit from status; the second is the direct marginal benefit from action $a$; the third is marginal cost.

The first analytical result stems from differentiating implicitly in Eq. (3) to give the individual's response to others:

$$
\frac{\partial a}{\partial a^{*}}=\frac{s v^{\prime \prime}\left(a-a^{*}\right)}{s v^{\prime \prime}\left(a-a^{*}\right)+(1-s) u^{\prime \prime}(a)-c^{\prime \prime}(a)}
$$

The denominator on the right-hand side of Eq. (4) is negative by the requirement that the maximization problem be concave. Hence the sign of the response of $a$ to $a^{*}$ depends upon the negative of the numerator. Comparison-concave utility, defined as $v^{\prime \prime}\left(a-a^{*}\right)<0$, therefore implies that a rise in others' actions leads the agent to increase his or her own action, $a$. Individuals with utility functions linear in comparisons $\left(v^{\prime \prime}\left(a-a^{*}\right)=0\right)$ act precisely independently of other people. Agents with comparison-convex utility behave in a way that deviates from other agents' behaviour: movements in $a^{*}$ induce them to alter their action in the opposite way from $a^{*}$.

Proposition 1. Under additive comparisons, 
individuals with comparison-concave utility follow others' actions;

(ii) individuals with comparison-linear utility ignore others;

(iii) individuals with comparison-convex utility do the opposite of others.

Proof. Direct from Eq. (4) and the concavity or convexity of $v($.$) .$

Intuitively, the reason for following behaviour is that, as actions elsewhere vary, the marginal utility of status changes. If other agents set high $a^{*}$, that reduces $a-a^{*}$, and this increases the marginal benefit from action $a$ for those with comparison-concave utility. The chosen level of $a$ therefore rises ${ }^{5}$. For example, consider a representative individual's response to an exogenous shock that causes the incomes of others in the community to rise, leading them to increase their consumption. Since her own income has not risen but her consumption rank has fallen, this individual experiences a decline in utility irrespective of the curvature of her utility function in relative consumption. If it is concave in consumption rank, then the marginal utility from increased consumption will be higher than before, so her best response to the shock is to consume more. But if her utility function is convex in rank, the marginal utility from increased consumption will be lower than before, so her best adjustment is to consume less. To say utility is convex in rank is simply to say that rank gets more useful, at the margin, the more one has of it. An exogenous decline in rank thus reduces the relative payoff from investing in rank and increases the relative payoff from investing in activities for which rank does not matter ${ }^{6}$.

The strength of following or deviant behaviour depends on the form of both the utility and the cost functions. In general, it is not possible to say whether individuals follow (or deviate) more strongly as $s$, the weight on status, rises. From (4), the sign of $\partial^{2} a / \partial a^{*} \partial s$ depends on $\left[s v^{\prime \prime}+(1-s) u^{\prime \prime}-c^{\prime \prime}\right] v^{\prime \prime}-s v^{\prime \prime}\left(v^{\prime \prime}-u^{\prime \prime}\right)$, where the term in square brackets is negative by concavity. Under comparisonconcave utility, $\left(v^{\prime \prime}<0\right)$ this expression cannot be signed in general: it is not

\footnotetext{
${ }^{5}$ The book on economic behaviour and status by Frank (1985) does not cover the points made in this paper, but it does touch upon imitative strategies: "It seems plausible to think of imitative behaviour as reflecting an inner desire to be like other people. Yet this description seems to miss something important ... our tendency to behave as others do may spring ... from a very rational fear that their information is better than ours. From this perspective we can view the desire to imitate as merely a way of trying to avoid being outdone" (p. 19). The paper shows that assumptions about information are not required, and that Frank's book could have explained imitation using the arguments he applied to explain many other phenomena.

${ }^{6}$ At a mathematical level, what determines the response of $a$ to $a^{*}$ is the cross-partial derivative of that part of the utility function. One might argue, therefore, that it is the algebraic complementarity of $a$ and $a^{*}$ that matters (Gary Becker has made this point to us). Another way of describing the shape of the comparisons part of the utility function appeals to the analogy with the textbook notion of risk-aversion over income. In this taxonomy, it is comparison-risk-averse individuals (i.e. those with comparison-concave utility) who follow others' actions, whereas comparison-risk-loving individuals do the opposite of others, and comparison-risk-neutral individuals act independently of others.
} 
always true that individuals follow more closely as the weight on status rises. However, with comparison-convex utility $\partial^{2} a / \partial a * \partial s$ is unambiguously negative: agents will behave more deviantly (i.e. $\partial a / \partial a *$ will be more negative) the higher is $s$.

A natural benchmark case is linear following, where $\partial a / \partial a *=1$. Consider the special case of maximand (1) given by

$$
\text { Maximize } s v\left(a-a^{*}\right)+(1-s) a-c a
$$

the first-order condition of which can be written as

$$
v^{\prime}\left(a-a^{*}\right)=\left(\frac{c+s-1}{s}\right) \text {. }
$$

The agent then matches changes in others' behaviour one-for-one. This requires $v\left(a-a^{*}\right)$ to be concave, to ensure a maximum.

This is, however, a special case which results from the linearity of $u($.$) and c($.$) .$ More generally, if cost is strictly convex (5) becomes

$$
\text { Maximize } s v\left(a-a^{*}\right)+(1-s) a-c(a)
$$

which gives the first-order condition

$$
s v^{\prime}\left(a-a^{*}\right)+1-s-c^{\prime}(a)=0 .
$$

In this case it can easily be verified that $\partial a / \partial a *<1$ and that the strength of following or deviancy depends on $s$.

These establish the result below.

Proposition 2. With comparison-concave utility, and maximand (5), there is linear one-for-one following. This is true for any weight on status, $s>0$. However, in general following is not linear and is dependent on $s$.

Proof. Direct from (6) (it can be seen that $a-a^{*}$ equals a constant, so $\mathrm{d} a=\mathrm{d} a *$ ), and from (4) and (8).

A likely reaction from some economists is that the assumption that status matters is tantamount to assuming a taste for emulation (so making the model uninteresting). This is incorrect: agents with comparison-linear utility, for example, do not follow one another. The model derives conformity in a framework where agents want to be different from one another.

The analytical results illustrate a fundamental characteristic of the class of models studied in the paper. When people value their relative position in society, and so get utility from being towards the top of a hierarchy of levels of action $a$, the assumption of comparison-concave utility is sufficient to generate 'following'. It is not necessary to assume that individuals care solely about status: the proof goes through if the weight $s$ on status is small. The detailed structure of the 
maximization problem is also unimportant to the derivation of imitative activity. Only the mild assumption of a local maximum is required. It is also straightforward to verify that the key result holds if the comparison utility component, $v($.$) , includes weighted levels of a$ and $a^{*}$.

In this framework, not everyone copies and acts conventionally. Agents who would enjoy risk (over relative position) act deliberately differently from the rest. Comparison-convex utility generates deviant behaviour $\left(\partial a / \partial a^{*}<0\right)$ which might be thought to conform to, and express formally, our intuitions about nonconformism in social and economic settings. The model therefore provides one account of deviancy, which has traditionally been a central issue in sociology.

Although the tenor of the results holds good for the case of ratio comparisons, the details of the argument are altered. The first order condition for a maximum of the function (2) is

$$
s v^{\prime}\left(\frac{a}{a^{*}}\right) \frac{1}{a^{*}}+(1-s) u^{\prime}(a)-c^{\prime}(a)=0
$$

The sign of the derivative of action $a$ with respect to others' actions $a^{*}$ is then

$$
\operatorname{sign} \frac{\partial a}{\partial a^{*}}=\operatorname{sign}\left\{-v^{\prime \prime}\left(\frac{a}{a^{*}}\right) \frac{a}{a^{*}}-v^{\prime}\left(\frac{a}{a^{*}}\right)\right\}
$$

Hence, following behaviour emerges if the comparison component of utility is concave enough (if the elasticity of marginal utility with respect to status exceeds unity); if $v($.$) is less concave, or convex, then the individual will behave$ deviantly ${ }^{7}$.

Proposition 3. Under ratio comparisons, the concavity associated with an elasticity of marginal utility with respect to status of unity marks the dividing line between followers and deviants.

Proof. Direct from Eq. (10).

\subsection{Altruism and conformism}

It might be argued that the model paints too gloomy a picture of human beings. As described, the function $v\left(a-a^{*}\right)$ implies that agents become happier as their own action $a$ outstrips others' actions $a^{*}$. Thus status operates through a form of envy effect.

The framework can be adapted, however, to an altruistic world. For example, consider the case in which individuals wish to maximize

\footnotetext{
${ }^{7}$ Appealing to the analogy between the curvature of the comparison component of utility, $v($.$) , and$ the notion of risk aversion, following behaviour results under ratio comparisons if the individual has comparison-risk-aversion of greater than unity.
} 


$$
U=s v\left(b a^{*}-\beta a\right)+(1-s) u(a)-c(a)
$$

where the comparison component of utility is now increasing in others' actions $a^{*}$ and decreasing in the own action $a$, and the parameters $b$ and $\beta$ capture the strength of the effects. Action $a$ still gives direct utility through the u(a) component. The first-order condition is derived in the usual way and the response of $a$ to $a^{*}$ is determined by

$$
\operatorname{sign} \frac{\partial a}{\partial a^{*}}=\operatorname{sign}\left\{-\operatorname{sb} \beta v^{\prime \prime}\left(b a^{*}-\beta a\right)\right\} \text {. }
$$

Once again, therefore, the assumption of concavity, this time with respect to the individual's concern for others, ensures that people follow one another. It is the sign of the second derivative, not of the first, that matters. Hence the key aspects of the analysis are not altered by allowing people to be pleased when others move ahead.

The model can be contrasted with the related theories of Akerlof (1980) and Kandel and Lazear (1992). These analyses assume that individuals experience direct disutility when they behave deviantly. In Akerlof (1982), reputation enters into the utility function, and reputation depends upon observance of a code of accepted behaviour. A theory of custom is thereby generated. In Kandel and Lazear (1992), the utility function includes a peer pressure function, by which non-conventional behaviour leads to costs for the individual. The authors' objective is to show how norms and the free rider problem interact.

While they deal with interesting issues, both studies are open to a traditional criticism. Akerlof (1982) and Kandel and Lazear (1992) effectively assume that economic and social agents enjoy conforming, and are aware that in doing so they depart from the standard economic approach of deriving behaviour from a set of more primitive axioms. The model developed in this paper pushes this process one stage further back. It does not assume that conformism enters the utility function. Instead, the model makes the assumption that utility depends partly upon rank or status, and that it does so in a concave way. If these assumptions are viewed as plausible and sufficiently primitive, the paper can be seen as offering a choicetheoretic explanation for the Akerlof-Kandel-Lazear framework.

\subsection{Equilibria and norms}

It is natural to consider the properties of an equilibrium in which many decision-makers act as the model suggests. Social and economic outcomes are then appropriately thought of as Nash equilibria in which people choose their desired action, $a$, given what others are doing. An equilibrium is a vector of consistent actions.

Assume a continuum of decision-makers, differentiated by different cost 
parameters $\alpha$. Let $\alpha$ be distributed in society $f(\alpha)$. Under additive comparisons, therefore, social welfare is given by

$$
W=\int\left\{s v\left(a-a^{*}\right)(1-s) u(a)-c(a, \alpha)\right\} f(\alpha) \mathrm{d} \alpha,
$$

where the mean action is

$$
a^{*}=\int a f(\alpha) \mathrm{d} \alpha
$$

For society to be at an optimum,

$$
\begin{aligned}
& a(\alpha): s v^{\prime}\left(a-a^{*}\right)+(1-s) u^{\prime}(a)-c_{a}(a, \alpha)-\lambda=0 \\
& a^{*}: \lambda-\int s v^{\prime}\left(a-a^{*}\right) f(\alpha) \mathrm{d} \alpha=0,
\end{aligned}
$$

where $\lambda$ is the multiplier on constraint (14). It follows, comparing (15) with the earlier Eq. (3) for privately rational actions, that equilibria are not optimal. By the concavity of Eq. (13), and from Eq. (15) and (16), socially desirable levels of action are below those that individuals take. This is because action affects the relative standing of others. The essential idea is that, when social comparisons motivate people, any form of social equilibrium will be inherently sub-optimal because people ignore the externalities their actions create.

When there are many decision-makers it is restrictive to assume that each compares himself or herself to the mean. Some agents' actions may be more important in forming comparisons than others. Rewrite the original agent's maximand as

$$
U=s v(a-j \hat{a})+(1-s) u(a)-c(a, \alpha)
$$

where $j$ is a vector of coefficients, $\hat{a}$ is a vector of others' actions, and an agent's type depends on a parameter in the cost function $\alpha$. In this formulation, the optimal action $a$ depends on each of the other a actions being taken, where the size of each effect rests upon the relevant coefficient in the $j$ vector.

Linearizing this system produces, as an approximation, a set of equations given by

$$
\hat{a}=J \hat{a}+\hat{\alpha}=[I-J]^{-1} \hat{\alpha}=\left[\sum_{t=0}^{\infty} J^{t}\right] \hat{\alpha}
$$

in which $\hat{\alpha}$ is the vector of cost parameters for the different decision-makers, $a$ is their chosen actions, and $J$ is a matrix of coefficients measuring how actions interact. The matrix $[I-J]^{-1}$, where $I$ is the identity matrix, provides a method of capturing a form of following multiplier. It measures the way in which actions in one segment of society feed through into actions elsewhere. Some exogenous change (through $\hat{\alpha}$ ), for example, will permeate through society. The process of 
moving to the new equilibrium will look like the introduction of a new norm that most emulate.

It may be useful also to illustrate the model's application to economic following. One example is the Japanese-style case of corporate cultures in which everyone works at high levels of effort. When performance gives status, either directly or through added earnings, the model predicts effort-following of this sort. Another example is investment by, for example, banks making loans to developing countries. When managers are rewarded on the basis of their success relative to other banks' managers, as is often supposed, the model predicts that, if they have comparison-concave utility, these investors will exhibit herd behaviour. A third example is the emulative consumption behaviour discussed by Duesenberry (1949).

\subsection{Equity theory and neutrality results}

Social psychology has two theories that are especially relevant to the model outlined earlier. One is equity theory, due to Adams (1963), which states that human beings strive in any relationship or exchange to ensure that, for person $\mathrm{i}$ and person $\mathrm{j}$,

$$
\frac{\text { Outcome (or reward) of } j}{\text { Input (or effort) of } j}=\frac{\text { Outcome (or reward) of } i}{\text { Input (or effort) of } i}
$$

The idea is that individual $\mathrm{i}$ has a comparison or reference person, $\mathrm{j}$, and reduces his or her own input until it is in line with that comparison person's ratio of reward to input ${ }^{8}$. Homans (1961) and Blau (1955) suggest similar theories of social exchange. Surveys of this work from the economist's perspective are given in Carruth and Oswald (1989) and Akerlof and Yellen (1990). The laboratory and field evidence is reasonably supportive of the theory: see Adams and Freedman (1976) for a review.

Economists have traditionally been hostile to formulations of this sort, seeing them as ad hoc and inconsistent with rational choice theory. However, the ratio rule of equity theory can be derived using the model developed earlier. It emerges, as might be expected, that a linear ratio rule is a special case.

\footnotetext{
${ }^{8}$ Furnham and Lewis (1986) contrast economic theory and social exchange theory. They say that "the difference lies in social exchange theory's interest in social norms and perception of individuals it is not so much that an individual is maximizing self-interest, but bending to the wind of cultural norms and expectations of reasonable and fair behaviour" (p. 20). This paper takes a different approach.
} 
Our derivation of equity theory's formula begins by assuming that the utility function takes a (pure ratio comparisons) constant elasticity form:

$$
U=\frac{1}{1-\gamma}\left(\frac{r(a) a}{\rho\left(a^{*}\right) a^{*}}\right)^{1-\gamma}-c a
$$

where $\gamma$ is constant and $c$ is a constant measuring the marginal cost of actions. The function $r(a)$ is the average return to action $a$, and $\mathrm{r}(\mathrm{a}) \mathrm{a}$ is the total return. The representative other agent has average return $\rho\left(a^{*}\right)$ and total return $\rho\left(a^{*}\right) a^{*}$.

Assume that the return function $r(a)$ has constant elasticity $\eta$. Then the first-order condition for a maximum is

$$
\left(\frac{r a}{\rho a^{*}}\right)^{-\gamma}(1+\eta) \frac{r}{\rho a^{*}}-c=0 .
$$

There is an equivalent condition for the representative other agent. Defining the equivalent of $\gamma$ in Eq. (21) for that agent as $\varnothing$, and the elasticity of the return function as $\psi$, the other first-order condition is

$$
\left(\frac{\rho a^{*}}{r a}\right)^{-\varnothing}(1+\psi) \frac{\rho}{r a}-k=0
$$

where $k$ is the marginal cost of action $a^{*}$. Multiply Eq. (21) throughout by $a$, and Eq. (22) throughout by $a^{*}$, and rewrite as

$$
\begin{aligned}
& \left(\frac{r a}{\rho a^{*}}\right)^{1-\gamma}(1+\eta)=c a \\
& \left(\frac{\rho a^{*}}{r a}\right)^{1-\varnothing}(1+\psi)=k a^{*} .
\end{aligned}
$$

Expressing these as a ratio of one to the other:

$$
\left(\frac{r a}{\rho a^{*}}\right)^{2-\gamma-\varnothing}=m \frac{a}{a^{*}}
$$

where $m$ is a constant given by $c(1+\psi) / k(1+\eta)$. Here the first agent gets 'outcome' $r a$ in return for 'input' $a$; the other gets $\rho a^{*}$ for $a^{*}$.

Eq. (25) is a generalization of the formula proposed in equity theory (Adams, 1963 inter alia) and social exchange theory. To see it in the exact form used in that 
literature, consider the case $\gamma=0.5, \varnothing=0.5, c=k$ and $\psi=\eta$. Hence, agents are identical and have square-root utility functions, and the model predicts:

$$
\frac{r a}{a}=\frac{\rho a^{*}}{a^{*}}
$$

namely, the equality of outcome-to-input ratios. This is also the equality of average returns.

As the earlier quote from Elster implies, some sociologists have opposed the economist's notions of optimizing at the margin. To show that 'prices' like rates of return can have small effects here, consider the following version of the model. Let $r$ be the rate of return to action $a$, and $\rho$ be the rate of return to action $a^{*}$. The total returns to the agents are again $r a$ and $\rho a^{*}$, respectively. Rewrite the utility function, in terms of these levels of reward, as

$$
U=s v\left(\frac{r a}{\rho a^{*}}\right)+(1-s) \mu(r a)-c(a)
$$

which implies that people use ratio comparisons. The neutrality of rates of return can be seen (without differentiation or further analysis) to result from two further assumptions. If $r=\rho$, so that agents face common incentives, the ratio $r / \rho$ in the maximand becomes unity. If the weight $s$ is large, so that considerations of status are important, the second term in the above equation is small. More formally, in the limit as $s \rightarrow 1$ and $r \rightarrow \rho$ :

$$
U=v\left(\frac{a}{a^{*}}\right)-c(a)
$$

and the marginal incentives $r$ and $\rho$ become irrelevant to decision-making.

Under additive comparisons, this neutrality result occurs less readily, because there is not automatic cancelling of $r$ and $\rho$. Nevertheless, when $v$ is given by the $\log$ of the difference between the return to actions $a$ and $a^{*}$, and $s=1$ and $r=\rho$, the first-order condition is

$$
\frac{1}{a-a^{*}}-c^{\prime}(a)=0
$$

Once again, therefore, marginal incentives play no role.

This class of neutrality results has implications for a range of economic settings. Taxes on working income, the rate of interest on retirement savings, the size of 
piece rates within factories ${ }^{9}$ - all these are subject to a general neutrality finding if relative position is sufficiently important ${ }^{10}$.

\subsection{Fads and rational noise trading}

A final economic illustration is as follows. In a well-known paper, Shiller (1984) has argued that the most plausible explanation for the volatile meanreverting behaviour of asset markets is the existence of 'fads', caused by fashion and social pressure, in speculators' decisions. The author did not propose an optimizing model, but argued by analogy with social activity.

It is possible to use the paper's framework to provide a choice-theoretic foundation for Shiller's work, and for the interesting but ad hoc noise trading models (such as Cutler et al., 1990) that came after it. The model is a special case of the earlier framework. It is essentially an application of Jensen's inequality.

Consider an investor choosing between a risky asset that will realize price $p$ with probability density $f(p)$ and a safe asset with return $z$. Let $a$ be the share of the portfolio in the risky asset. Then the expected utility of an investor concerned with both absolute return (per dollar invested) and his or her relative return (where $a^{*}$ is what other investors do) is

$$
E U=\int\left\{v\left(p a+z(1-a)-p a^{*}-z\left(1-a^{*}\right)\right)+u(p a+z(1-a))\right\} f(p) \mathrm{d} p .
$$

\footnotetext{
${ }^{9}$ An analysis of how concern for status may affect a firm's internal wage structure is given in Frank (1985). Its predictions are not widely different, however, from those in some conventional models, like Carmichael (Carmichael, 1983, 1989), Harris and Holmstrom (1982), Hutchens (1989), Lazear (Lazear, 1979, 1981), Malcomson (1984), and Oswald (Oswald, 1981, 1984). Marsden (1986) discusses how sociological ideas, and concepts of fairness, might be incorporated into labour market theory.

${ }^{10}$ The following result illustrates how conventional life-cycle theory results can be overturned.
} Assume lifetime utility with periods 1 and 2 :

$$
V=V\left(\frac{c_{1}}{c_{1}^{*}}, \frac{c_{2}}{c_{2}^{*}}\right)
$$

where $c^{*}$ is others' consumption and $c$ is the individual's consumption. Budget constraints are

$$
y=c_{1}+\frac{c_{2}}{1+r}
$$

Hence

$$
y^{*}=c_{1}^{*}+\frac{c_{2}^{*}}{1+r}
$$

Thus the interest rate, $r$, cancels out. This is a well-defined concave problem and the optimal choice of savings (given others' decisions) is independent of the rate of interest. 
Write this more succinctly as

$$
\text { Maximize } E\{v+u\} \text {, }
$$

which has first-order condition

$$
E\left\{\left[v^{\prime}(\cdot)+u^{\prime}(\cdot)\right](p-z)\right\}=0 .
$$

Hence

$$
\operatorname{sign} \frac{\partial a}{\partial a^{*}}=\operatorname{sign}-E\left\{v^{\prime \prime}(\cdot)(p-z)^{2}\right\},
$$

which is positive under the assumption of concavity or risk-aversion with respect to relative return. Investors follow others. They do so because, in a world where relativities matter, emulation offers a kind of insurance.

This provides a model of rational noise trading, or herd behaviour, and rests upon the assumption that investors care in part about their performance relative to other investors. The common practice of linking fund managers' remuneration to their success relative to a market index will produce herd behaviour in financial markets, as income is dependent on status.

\section{Fads and following: some simulations}

Consider an economy with two types of agent: 'leaders' (subscript 1) and 'followers' (subscript $n$ ). The utility of both is given by the weighted sum of two quadratic functions, representing utility from the relative and absolute value of the action respectively. Time lags in information are assumed, so that individuals react to past values of $a^{*}$. The unit costs of activity $a$ are $c_{1}$ for leaders and $c_{n}$ for followers.

$$
\begin{aligned}
U_{1}= & s_{1} \beta_{0}\left(a_{1 t}-a_{n t-1}\right)+s_{1} \beta_{1}\left(a_{1 t}-a_{n t-1}\right)^{2}+\left(1-s_{1}\right) \beta_{2} a_{1 t} \\
& +\left(1-s_{1}\right) \beta_{3} a_{1 t}^{2}-c_{1} a_{1 t} \\
U_{n}= & s_{n} \gamma_{0}\left(a_{n t}-a_{1 t-1}\right)+s_{n} \gamma_{1}\left(a_{n t}-a_{1 t-1}\right)^{2}+\left(1-s_{n}\right) \gamma_{2} a_{n t}+\left(1-s_{n}\right) \gamma_{3} a_{n t}^{2} \\
& -c_{n} a_{n t}
\end{aligned}
$$

The direct component of utility is increasing and concave for both leaders and followers $\left(\beta_{2}, \gamma_{2}>0 ; \beta_{3}, \gamma_{3}<0\right)$. Leaders have comparison-convex relative utility $\left(\beta_{0}, \beta_{1}>0\right)$, while that of followers is comparison-concave $\left(\gamma_{0}>0 ; \gamma_{1}<0\right)$.

The maximisation of (34) and (35) yields the following equations:

$$
\begin{aligned}
& a_{1 t}=\left(c_{1}-s_{1} \beta_{0}-\left(1-s_{1}\right) \beta_{2}+2 s_{1} \beta_{1} a_{n t-1}\right) /\left(2 s_{1} \beta_{1}+2\left(1-s_{1}\right) \beta_{3}\right) \\
& a_{n t}=\left(c_{n}-s_{n} \gamma_{0}-\left(1-s_{n}\right) \gamma_{2}+2 s_{n} \gamma_{1} a_{1 t-1}\right) /\left(2 s_{n} \gamma_{1}+2\left(1-s_{n}\right) \gamma_{3}\right)
\end{aligned}
$$


The second-order conditions ensure that both denominators are negative. Leaders' actions move in the opposite direction to those of followers in the previous period, while followers emulate leaders' lagged actions.

Combining (36) and (37) gives the following difference equations:

$$
\begin{aligned}
a_{1 t}= & {\left[\left(\left(c_{1}-s_{1} \beta_{0}-\left(1-s_{1}\right) \beta_{2}\right) G+s_{1} \beta_{1}\left(c_{n}-\left(1-s_{n}\right) \gamma_{2}\right)\right) / 2 B G\right] } \\
& +s_{1} \beta_{1} s_{n} \gamma_{1} a_{1 t-2} / B G \\
a_{n t}= & {\left[\left(\left(c_{n}-s_{n} \gamma_{0}-\left(1-s_{n}\right) \gamma_{2}\right) B+s_{n} \gamma_{1}\left(c_{1}-\left(1-s_{1}\right) \beta_{2}\right)\right) / 2 B G\right] } \\
& +s_{1} \beta_{1} s_{n} \gamma_{1} a_{n t-2} / B G
\end{aligned}
$$

where $B=s_{1} \beta_{1}+\left(1-s_{1}\right) \beta_{3}$ and $G=s_{n} \gamma_{1}+\left(1-s_{n}\right) \gamma_{3}{ }^{11}$. The following proposition can then be stated.

Proposition 4. Cycles will occur if the slope coefficient in Eq. (38) and (39) is negative, i.e. if either $\beta_{1}$ or $\gamma_{1}$, but not both, are negative.

Proof. Directly from Eq. (38) and (39).

Cycles occur if one, but not both, of the types of agent has comparison-concave utility.

\subsection{Response to shocks}

The following simulations show how cycles result from a shock. The leaders' utility function is parameterised as $\beta_{0}=0.5, \beta_{1}=0.1, \beta_{2}=0.5$ and $\beta_{3}=-0.1$; the weight on relative action, $s_{1}$, is set to $\frac{1}{3}$ and the unit cost of action, $c_{1}$, equals 0.1 . For followers, $\gamma_{0}=0.5, \gamma_{1}=-0.1, \gamma_{2}=0.5$ and $\gamma_{3}=-0.1$; the weight on relative action, $s_{n}$, is set to $\frac{2}{3}$ and the unit cost of action, $c_{n}$, also equals 0.1 . Leaders thus put less weight on the relative part of utility than do followers. Agents are initially in equilibrium and the shock occurs at time $t=10$. Fig. 1 maps out the reaction to

${ }^{11}$ The equilibrium values of these equations are

$$
\begin{aligned}
a_{1}^{e}= & {\left[\left(c_{1}-s_{1} \beta_{0}-\left(1-s_{1}\right) \beta_{2}\right)\left(s_{n} \gamma_{1}+\left(1-s_{n}\right) \gamma_{3}\right)+s_{1} \beta_{1}\left(c_{n}-s_{n} \gamma_{0}-\left(1-s_{n}\right) \gamma_{2}\right)\right] } \\
& / 2\left(s_{1} \beta_{1}\left(1-s_{n}\right) \gamma_{3}+\left(1-s_{1}\right) \beta_{3} s_{n} \gamma_{1}+\left(1-s_{1}\right) \beta_{3}\left(1-s_{n}\right) \gamma_{3}\right) \\
a_{n}^{e}= & {\left[\left(c_{n}-s_{n} \gamma_{0}-\left(1-s_{n}\right) \gamma_{2}\right)\left(s_{1} \beta_{1}+\left(1-s_{1}\right) \beta_{3}\right)+s_{n} \gamma_{1}\left(c_{1}-s_{1} \beta_{0}-\left(1-s_{1}\right) \beta_{2}\right)\right] } \\
& / 2\left(s_{1} \beta_{1}\left(1-s_{n}\right) \gamma_{3}+\left(1-s_{1}\right) \beta_{3} s_{n} \gamma_{1}+\left(1-s_{1}\right) \beta_{3}\left(1-s_{n}\right) \gamma_{3}\right)
\end{aligned}
$$

It is not clear whether $a_{1}^{\mathrm{e}}$ is greater or less than $a_{n}^{\mathrm{e}}$. With the assumptions that $c_{1}=c_{n}, \gamma_{0}=\beta_{0}, \gamma_{2}=\beta_{2}$ and $\gamma_{3}=\beta_{3}$, and that $c_{1}$ is less than $\beta_{0}$, which are made for the simulations, it is easy to show that a sufficient condition for $a_{n}^{\mathrm{e}}$ to be greater than $a_{1}^{\mathrm{e}}$ is that $s_{n}$ is greater than $s_{1}$, i.e. that followers put more weight on the returns from absolute utility than do leaders. 


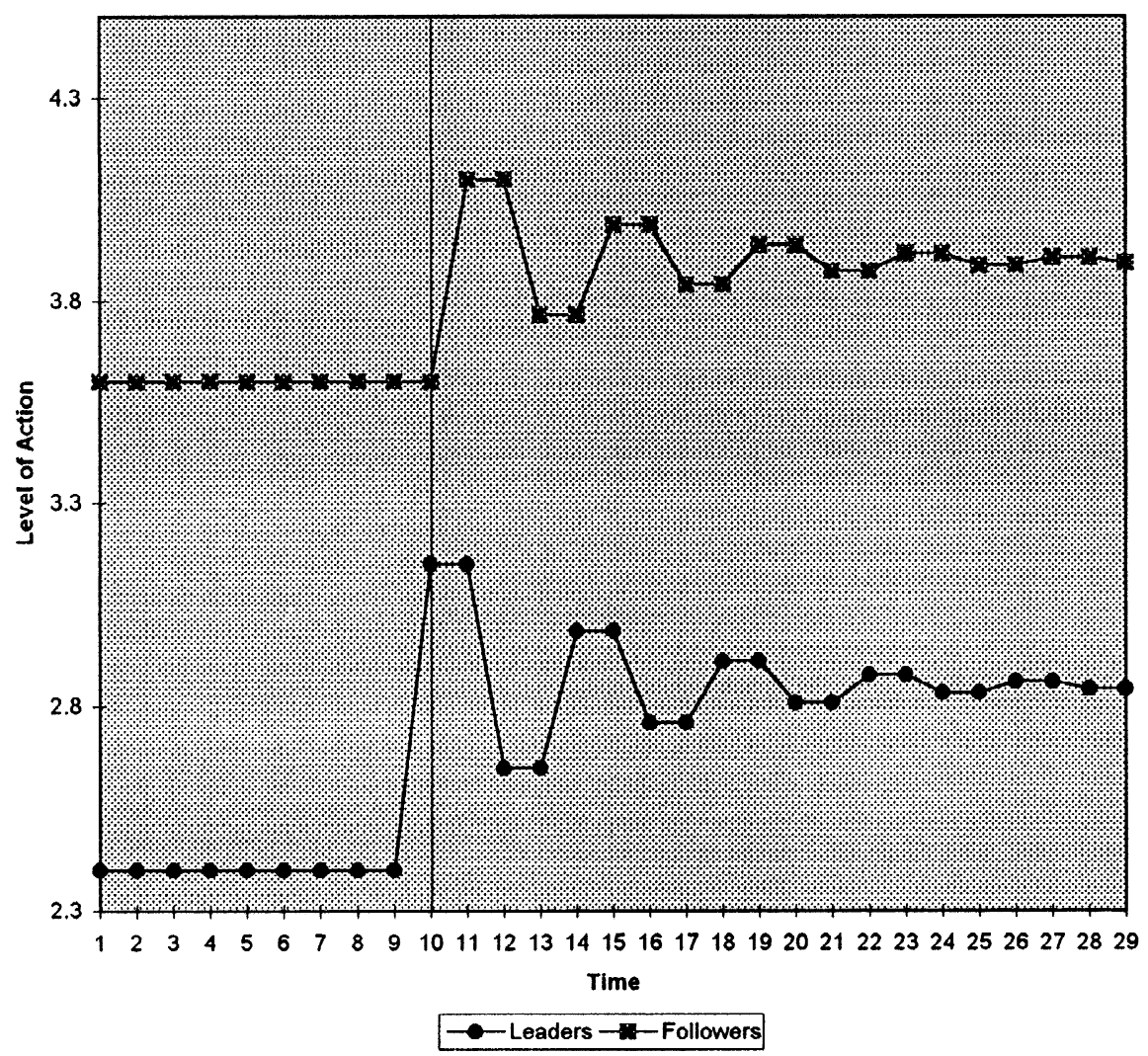

Fig. 1. Cycles resulting from a fall in leaders' costs.

a fall in leaders' costs (from 0.1 to 0.05 ). The parameter values produce cycles which largely die away about fifteen time periods after the initial shock. The new equilibrium entails greater levels of the action for both leaders and followers.

\subsection{The perverse response of demand to positive information or lower prices}

Imagine that a good becomes more attractive, as reflected by an increase in $\beta_{2}$ and $\gamma_{2}$ in Eq. (34) and (35); this acts as a positive shock to marginal utility. In a model without comparisons, consumers' response would be to increase $a$ until the concavity of the utility function brought marginal benefit back into equality with marginal cost. More complicated effects arise when status matters, as others' actions affect marginal utility. Followers emulate leaders, while the latter react deviantly to such emulation. Higher $a_{n t}$ reduces the marginal utility of $a$ for leaders, while higher $a_{1 t}$ has the opposite effect for followers. Both derive utility 
from status: the difference in their response comes from the concavity/convexity of the comparisons component of utility.

A positive shock to marginal utility may reduce the total level of the action in equilibrium. In the above case, this arises if $\left(1-s_{1}\right) \beta_{2}\left(2 s_{n} \gamma_{1}+\left(1-s_{n}\right) \gamma_{3}\right)+(1-$ $\left.s_{n}\right) \gamma_{2}\left(2 s_{1} \beta_{1}+\left(1-s_{1}\right) \beta_{3}\right)>0$. The first half of the above inequality is negative while the second half is ambiguously signed. Inspection reveals that a large value of $\gamma_{2}$ compared to $\beta_{2}$, and a small absolute value of $\beta_{3}$ compared to $\beta_{1}$ will ensure that this inequality holds. Some further constraints on acceptable parameter values result from the second order conditions and from the requirement that the equilibrium level of actions be positive. The existence of this perverse demand effect depends crucially on the model's utility parameters and on the relative numbers of followers and leaders ${ }^{12}$.

\subsection{Snob effects and popularity peaks}

More complicated dynamics can be generated by specifying endogenous changes in behaviour. A snob effect comes about if some leaders do not wish to be associated with an action that has become 'too popular'. It can be modelled by imagining that for each leader $i$ there is a threshold of the level of followers' actions, $\bar{a}_{n i}$, such that if $a_{n t} \geq \bar{a}_{n i}$ then $a_{1 i t+1}=0$. If $\bar{a}_{n i}$ has some kind of standard distribution, then the same type of cyclical behaviour follows a shock, but with cycles of greater amplitude and of longer duration. Followers are at times avidly engaged in activities which leaders are disavowing (because they have become too popular). The equilibrium values of both $a_{1}$ and $a_{n}$ are lower than those which prevailed in the model without the snob effect. Leaders who are sensitive to the popularity of the action among followers will have zero levels of action in equilibrium if $a_{n}^{\mathrm{e}}>\bar{a}_{n i}$.

On a longer time-scale, we can ask if leaders return to actions that were once popular with the same enthusiasm as before. The popularity of neighbourhoods, such as Islington in London or Bastille in Paris, suggests that, in the long run, they do. But in the shorter run leaders may be very sensitive to activities that are going

\footnotetext{
${ }^{12}$ An example suffices to prove the existence of this phenomenon. Taking $s_{1}=0.4, s_{n}=0.6, c_{1}=0.05$, $c_{n}=0.4, \beta_{0}=1.5, \beta_{1}=\beta_{2}=0.2, \beta_{3}=-0.2, \gamma_{0}=0.5, \gamma_{1}=-0.05, \gamma_{2}=1$ and $\gamma_{3}=-0.5$, the equilibrium value of $\mathrm{a}_{1}$ is 1.079 and that of $a_{n}$ is 3.648 , for a total level of ' $a$ ' of 4.727 . Increasing both terms in the level of absolute utility by $10 \%$ (i.e. $\beta_{2}$ rises to 0.22 and $\gamma_{2}$ rises to 1.1 ) raises $a_{n}$ to 3.871 , but reduces $a_{1}$ to 0.784 , for a total level of action of 4.655 . The total level of action falls after the positive shock to marginal utility. Researchers in the field of drug policy have often wondered at the apparent fall in the use of cannabis in Holland following its 1976 decriminalisation (see van Kalmthout, 1989). This paper's model suggests one explanation. The positive signal about the effects of drugs that decriminalisation gave, or equivalently any accompanying fall in price, initially led both leaders and followers to increase use. However, if there are enough leaders, and if they are sufficiently sensitive to followers' actions, a substantial reduction of leaders' drug use may bring about a reduction in overall drug use in equilibrium.
} 
out of fashion. This can be modelled by reducing the $\beta$ parameters in the leaders' utility function once an activity peaks in popularity. The familiar cycle follows a shock, but with a clear downward trend. In the long run it may be the low level of the activity that spurs leaders to take it up again, because they are attracted to activities which have been out of fashion for a sufficiently long period of time or because the activities become cheap. If leaders are relatively price sensitive (because they are young or poor) then they will be attracted back to unfashionable places more readily than are followers. A model which incorporated both of these features would be able to describe both short-run and long-run cycles in fashion.

\section{Conclusion}

This paper describes a theory of rational emulation and deviance. The model of social and economic action in the paper rests upon a simple point. Concern for status or relative position, coupled with a concave utility function, leads to 'following' behaviour. When their peers start to act in a particular way, individuals find, if they have comparison-concave utility, that their own marginal utility from acting that way increases. To an outside observer, it will appear (wrongly) that individuals get utility from being the same as other people.

The paper studies and builds upon this theory of following behaviour. It treats the individual decision-maker as a convex combination of economic man and sociological man, and draws six main additional conclusions:

1. Those with convex utility from relative position will act deviantly.

2. Private rates-of-return may have little effect upon decisions.

3. The analysis provides a choice-theoretic justification for the kinds of behavioural rules predicted by social psychologists (such as in Adams' equity theory and Homans' social exchange theory).

4. The paper demonstrates that models in which it is assumed that people have a taste for conformity can be justified at a more primitive axiomatic level by appealing to comparison-concave utility.

5. A simple model with relative utilities can lead to cycles in fashion.

6. Social and economic norms can be thought of as Nash equilibria of the following-game described in the paper. Social outcomes are generically suboptimal.

The pivotal role in this paper's analysis is the concept of the concavity of the status component of utility. We believe that it may turn out to be useful in other areas. 


\section{Acknowledgements}

We began work on this some years ago while at the London School of Economics. Since then, a literature on herd behaviour has grown rapidly, but does not seem to have suggested the approach developed here. We are grateful to Daron Acemoglu for many discussions about herd behaviour and relative comparisons, to Peter Abell, Gary Becker, Claire Fabre, Bob Frank, Morten Hviid, Steve Jones, Bob Solow, Max Steuer, Philip Trostel, Thierry Verdier and two anonymous referees for helpful advice, and to participants in the 1996 International Seminar in Public Economics for comments. Bob Solow corrected a confusion in an earlier draft. This paper is part of an ESRC-sponsored project on inter-disciplinary research.

\section{References}

Abell, P., 1971. Model Building in Sociology. Schocken, New York.

Abell, P., 1992. Is Rational Choice Theory a Rational Choice of Theory? In: Coleman, J.S., Fararo, T.J. (Eds.), Rational Choice Theory: Advocacy and Critique. Sage, London.

Adams, J.S., 1963. Toward an Understanding of Inequity. Journal of Social Psychology 67, 422-436.

Adams, J.S., 1965. Inequity in Social Exchange. In: Berkowitz, L. (Ed.), Advances in Experimental Social Psychology, 2. Academic Press, New York and London.

Adams, J.S., Freedman, S., 1976. Equity Theory Revisited: Comments and Annotated Bibliography. In: Berkowitz, L., Walster, E. (Eds.), Advances in Experimental Social Psychology, 9. Academic Press, New York.

Akerlof, G.A., 1980. A Theory of Social Custom, of Which Unemployment May be One Consequence. Quarterly Journal of Economics 94, 749-775.

Akerlof, G.A., 1982. Labor Contracts as Partial Gift Exchange. Quarterly Journal of Economics 97, 543-569.

Akerlof, G.A., Yellen, J.L., 1990. The Fair Wage - Effort Hypothesis and Unemployment. Quarterly Journal of Economics 105, 255-284.

Argyle, M., 1989. The Social Psychology of Work, second ed. Penguin Press, Harmondsworth.

Banerjee, A.V., 1992. A Simple Model of Herd Behaviour. Quarterly Journal of Economics 107, 797-818.

Baxter, J.L., 1988. Social and Psychological Foundations of Economic Analysis. Harvester Wheatsheaf, New York.

Becker, G.S., 1974. A Theory of Social Interactions. Journal of Political Economy 82, 1063-1093.

Becker, G.S., 1976. The Economic Approach to Human Behaviour. University of Chicago Press, Chicago.

Bernheim, B.D., 1994. A Theory of Conformity. Journal of Political Economy 102, 841-877.

Bernstein, M., Crosby, F.J., 1980. An Empirical Examination of Relative Deprivation Theory. Journal of Experimental Social Psychology 16, 442-456.

Blau, P.M., 1955. The Dynamics of Bureaucracy: A Study of Interpersonal Relations in Two Government Agencies. Chicago University Press, Chicago.

Boskin, M., Sheshinski, E., 1978. Optimal Redistributive Taxation When Individual Welfare Depends Upon Relative Income. Quarterly Journal of Economics 92, 589-601.

Bottomore, T.B., 1966. Sociology. In: MacKenzie, N. (Ed.), A Guide to the Social Sciences. Weidenfeld and Nicolson, London. 
Bulow, J., Klemperer, P., 1991. Rational Frenzies and Crashes. NBER Technical Working Paper No. 112.

Carmichael, L., 1983. Firm-Specific Human Capital and Promotion Ladders. Bell Journal of Economics 14, 251-258.

Carmichael, L., 1989. Self-Enforcing Contracts, Shirking, and Life Cycle Incentives. Journal of Economic Perspectives 3, 49-64.

Carruth, A.A., Oswald, A.J., 1989. Pay Determination and Industrial Prosperity. Oxford University Press, Oxford and New York.

Clark, A.E., Oswald, A.J., 1996. Satisfaction and Comparison Income. Journal of Public Economics 61, 359-381.

Cole, H.L., Mailath, G.J., Postlewaite, A., 1992. Social Norms, Savings Behaviour and Growth. Journal of Political Economy 100, 1092-1125.

Coleman, J.S., 1991. The Foundation of Social Theory. Harvard University Press, Cambridge MA.

Crosby, F.J., 1976. A Model of Egoistical Relative Deprivation. Psychological Review 83, 85-113.

Cutler, D.M., Poterba, J.M., Summers, L.H., 1990. Speculative Dynamics and the Role of Feedback Traders. American Economic Review, Papers and Proceedings 80, 63-68.

Davis, J.A., 1959. A Formal Interpretation of the Theory of Relative Deprivation. Sociometry 22, 280-296.

Duesenberry, J.S., 1949. Income, Saving and the Theory of Consumer Behaviour. Harvard University Press, Cambridge.

Elster, J., 1991. The Cement of Society. Cambridge University, Cambridge.

Fershtman, C., Weiss, Y., 1992. Social Status, Culture and Economic Performance. mimeo, Tel Aviv University.

Festinger, L., 1954. A Theory of Social Comparison Processes. Human Relations 7, 117-140.

Frank, R.H., 1984. Are Workers Paid Their Marginal Products?. American Economic Review 74, 549-571.

Frank, R.H., 1984. Interdependent Preferences and the Competitive Wage Structure. Rand Journal of Economics 15, 510-520.

Frank, R.H., 1985. Choosing the Right Pond: Human Behaviour and the Quest for Status. Oxford University Press, London and New York.

Furnham, A., Lewis, A., 1986. The Economic Mind. Wheatsheaf Books, Brighton.

Gylfason, T., Lindbeck, A., 1984. Union Rivalry and Wages: An Oligopolistic Approach. Economica 51, 129-139.

Harris, M., Holmstrom, B., 1982. A Theory of Wage Dynamics. Review of Economic Studies 49, 315-333.

Hochman, H.M., Rogers, J.D., 1969. Pareto Optimal Redistribution. American Economic Review 59, $542-557$.

Homans, G.C., 1961. Social Behaviour: Its Elementary Forms. Harcourt Brace, New York.

Hutchens, R.M., 1989. Seniority, Wages and Productivity: A Turbulent Decade. Journal of Economic Perspectives 3, 49-64.

Jones, S.R.G., 1984. The Economics of Conformism. Blackwell, Oxford.

van Kalmthout, A., 1989. Characteristics of Drug Policy in the Netherlands. In: Albrecht, H.-J., van Kalmthout, A. (Eds.), Drug Policies in Western Europe. Max Planck Institute, Freiburg.

Kandel, E., Lazear, E.P., 1992. Peer Pressure and Partnerships. Journal of Political Economy 100, 801-817.

Kapteyn, A., Van Herwaarden, F.G., 1980. Interdependent Welfare Functions and Optimal Income Distribution. Journal of Public Economics 14, 375-397.

Kosicki, G., 1987. A Test of the Relative Income Hypothesis. Southern Economic Journal 54, 422-434.

Lawler, E.E., 1971. Pay and Organizational Effectiveness: A Psychological View. McGraw Hill, New York.

Layard, R., 1980. Human Satisfactions and Public Policy. Economic Journal 90, 737-750. 
Lazear, E.P., 1981. Agency, Earnings Profiles, Productivity, and Hours Restrictions. American Economic Review 71, 606-620.

Lazear, E.P., 1979. Why Is There Mandatory Retirement?. Journal of Political Economy 87, 12611284.

Lommerud, K.E., 1989. Educational Subsidies When Relative Income Matters. Oxford Economic Papers 41, 640-652.

Malcomson, J.M., 1984. Work Incentives, Hierarchy and Internal Labor Markets. Journal of Political Economy 92, 486-507.

Marsden, D., 1986. The End of Economic Man? Wheatsheaf Books, Brighton.

Oswald, A.J., 1979. Wage Determination in an Economy with Many Trade Unions. Oxford Economic Papers 31, 369-385.

Oswald, A.J., 1981. The Theory of Internal Wage and Employment Structure. Bell Journal of Economics 12, 263-271.

Oswald, A.J., 1983. Altruism, Jealousy and the Theory of Optimal Non-Linear Taxation. Journal of Public Economics 20, 77-87.

Oswald, A.J., 1984. Wage and Employment Structure in an Economy with Internal Labor Markets. Quarterly Journal of Economics 99, 693-716.

Pollis, N.P., 1968. Reference Groups Re-examined. British Journal of Sociology 19, 300-307.

Pritchard, R.D., 1969. Equity Theory: A Review and Critique. Organizational Behaviour and Human Performance 4, 176-211.

Rauscher, M., 1992. Keeping up with the Joneses: Chaotic Patterns in a Status Game. Economics Letters 40, 287-290.

Robson, A.J., 1992. Status, the Distribution of Wealth, Private and Social Attitudes to Risk. Econometrica 60, 837-858.

Runciman, W.G., 1966. Relative Deprivation and Social Justice. Routledge and Kegan Paul, Henley.

Scharfstein, D., Stein, J., 1990. Herd Behaviour and Investment. American Economic Review 80, 465-479.

Sen, A.K., 1983. Poor, Relatively speaking?. Oxford Economic Papers 35, 153-169.

Scitovsky, T., 1976. The Joyless Economy. Oxford University Press, New York.

Shiller, R.J., 1984. Stock Prices and Social Dynamics. Brookings Papers on Economic Activity 2, 457-510.

Sinclair, P.J.N., 1990. The Economics of Imitation. Scottish Journal of Political Economy 37, 113-144.

Steuer, M., 1989. Culture and Optimality. London School of Economics, STICERD, Discussion Paper TE $89 / 206$.

Stouffer, S.A. et al., 1949. The American Soldier. Princeton University Press, Princeton.

Trevithick, J.A., 1976. Money Wage Inflexibility and the Keynesian Labour Supply Function. Economic Journal 86, 327-332.

Van de Stadt, H., Kapteyn, A., Van de Geer, S., 1985. The Relativity of Utility: Evidence from Panel Data. Review of Economics and Statistics 67, 179-187.

Veblen, T., 1949. The Theory of the Leisure Class. George Allen and Unwin, London. Originally published 1899 by Macmillan, New York.

Walster, E., Walster, G.W., Berscheid, E., 1973. New Directions in Equity Research. Journal of Personality and Social Psychology 25, 151-176.

Warr, P., 1985. Psychology at Work. Penguin Books, Harmondsworth.

Weik, K.E., 1966. The Concept of Equity in the Perception of Pay. Administrative Science Quarterly 11, 414-439.

Weyant, J.M., 1986. Applied Social Psychology. Oxford University Press, New York.

Wood, A., 1978. A Theory of Pay. Cambridge University Press, Cambridge. 